\title{
Amamentação: um híbrido natureza-cultura
}

\author{
Breastfeeding: a nature-culture hybrid
}

\author{
João Aprigio Guerra de Almeida ${ }^{1}$, Franz Reis Novak ${ }^{2}$
}

\section{Resumo}

Objetivo: Contribuir para a construção de uma nova síntese teórica das inter-relações entre o biológico e o social no cenário da amamentação, categorizando-a com um híbrido natureza-cultura.

Fontes dos dados: Foram utilizados os referenciais metodológicos da pesquisa qualitativa em saúde, adotando-se os preceitos da hermenêutica-dialética para análise dos dados. A técnica de pesquisa utilizada foi a análise documental de fontes primárias, contemplando documentos históricos, livros, artigos científicos e teses de medicina escritas nos séculos 19 e 20.

Síntese dos dados: Dependendo do momento histórico e da intencionalidade atribuída ao ato de amamentar, os aspectos relacionados à natureza e à cultura, ou seja, à biologia e à sociedade, ora se separam, ora se mesclam. A abordagem compreensiva da amamentação permite perceber, por vezes, que um hábito cultural, para ser assimilado, foi tratado como instintivo, natural e biológico, ao qual não cabe nenhum tipo de questionamento. Em outras oportunidades, particularmente no curso da última década, o tradicional reducionismo biológico vem observando uma progressiva tendência de substituição, cedendo lugar a interpretações culturais que não reduzem o ser humano à condição de um mamífero qualquer. Focada sob este prisma, a amamentação, além de biologicamente determinada, é socioculturalmente condicionada, tratando-se, portanto, de um ato impregnado de ideologias e determinantes que resultam das condições concretas de vida. Na configuração real, um processo aparentemente tão natural, tão carregado de afeto e emoção, em verdade congrega os mais agressivos interesses mercadológicos, muitas vezes mascarados de conhecimentos científicos e travestidos de dispositivos para a saúde.

Conclusão: A amamentação focada como um híbrido naturezacultura simboliza as mudanças teórico-metodológicas ocorridas especialmente no final da década de 90 . Essas mudanças correspondem a uma revalorização da biologia e a um aprofundamento nos processos interdisciplinares.

J Pediatr (Rio J). 2004;80(5 Supl):S119-S125: Aleitamento materno, amamentação, relação natureza-cultura.

\section{Abstract}

Objective: To contribute to the creation of a new theoretical synthesis about the relationship between the biological and social dimensions of breastfeeding, categorizing it as a nature-nurture hybrid.

Sources of data: The methodological approach of the present article was based on the qualitative health research frame, and data were analyzed on the basis of dialectic-hermeneutic principles. Primary sources, comprising historical documents, books, scientific articles and medical theses written in the 19th and 20th centuries were analyzed.

Summary of the findings: Depending on the moment in history and on the expectations that surround the act of breastfeeding, the aspects related to nature and nurture, i.e., to biology and society, sometimes separate out and sometimes intermingle. A comprehensive approach to breastfeeding makes possible to see that it had to be considered instinctive, natural and biological in order to be assimilated as a cultural habit, and thus, it is not open to any kind of questioning. On other occasions, particularly in the course of the past decade, there has been a steady tendency to supplant traditional biological reductionism, which yielded cultural interpretations that do not reduce the human being to the status of a mammal like any other. Under this point of view, breastfeeding, in addition to being biologically determined, is socially conditioned, and thus constitutes an act embedded in ideologies and determinants resulting from the concrete conditions of life. In real life, however, a process apparently so natural, so loaded with affection and emotion is, in fact, affected by the most aggressive market interests, very often presented as scientific knowledge and decked out as health provisions.

Conclusion: Breastfeeding focused as a nature-culture hybrid symbolizes the theoretical and methodological changes in the field, especially in the late 1990 s. These changes reflect a renewed appreciation of biology and a more in-depth approach to interdisciplinary processes.

J Pediatr (Rio J). 2004;80(5 Supl):S119-S125: Breastfeeding, nature-culture relationship.

\section{Introdução}

As questões relacionadas à prática da amamentação têm-se configurado objeto de interesse para diferentes atores e grupos sociais ao longo da história. Em todas as épocas, o ser humano foi levado a construir rotas alternativas para responder à demanda das mulheres que, por opção ou imposição, trilharam o caminho do desmame precoce. Desde a secular figura da ama-de-leite até a 
emblemática vanguarda científica construída pelo marketing dos fabricantes de leites modificados, a alimentação do lactente tem servido a propósitos que não se circunscrevem exclusivamente às questões ligadas à saúde, denotando, em muitas situações, interesses relacionados à modulação de comportamento social e à oportunidade de auferir lucros de toda espécie ${ }^{1}$.

A amamentação, além de biologicamente determinada, é socioculturalmente condicionada, tratando-se, portanto, de um ato impregnado de ideologias e determinantes que resultam das condições concretas de vida. Por intermédio da análise compreensiva, sob a perspectiva do realismo histórico, torna-se possível evidenciar os condicionantes sociais, econômicos, políticos e culturais que a transformaram em um ato regulável pela sociedade ${ }^{2}$. Dependendo da realidade social a ser considerada, a ambigüidade amamentação/desmame pode traduzir-se como um embate entre saúde e doença, entendendo-se que esses processos se associam em todos os momentos a variáveis econômicas e sociais. A dinâmica dessas relações, no que concerne às questões estruturais, termina por configurar a amamentação como um dos atributos que caracterizam a maternidade como um bem social compartilhado ${ }^{1}$.

Por outro lado, o paradigma de amamentação ora estabelecido é fruto de uma construção do movimento higienista e remonta ao século $19^{2}$. Como conseqüência, as estratégias de promoção da amamentação comumente praticadas estão impregnadas do reducionismo biológico típico do modelo oitocentista ${ }^{3}$, marcado pela incapacidade de lidar com a ambivalência que se estabelece, para a mulher, entre o querer e o poder amamentar ${ }^{4}$. As ações caracterizam-se pela verticalidade das construções e seguem a ideologia que reduz a prática da amamentação a um atributo natural, comum a todas as espécies de mamíferos, simbolicamente traduzida em slogans do tipo "amamentar é um ato natural, instintivo, biológico e próprio da espécie". Com esse pano de fundo, as ações propugnadas se orientam, invariavelmente, para informar a mulher sobre as vantagens em ofertar o seio a seu filho e por responsabilizála pelos resultados futuros, decorrentes do sucesso ou do fracasso ${ }^{1}$. A lógica de "informar para responsabilizar" procura modular o comportamento da mulher em favor da amamentação, imputando-lhe culpa pelo desmame precoce, que é associado de forma direta a agravos para a saúde de seu filho.

Este modelo assistencial, verticalizado e impositivo, há muito se revela esgotado, incapaz de responder às demandas da mulher em processo de amamentação. A construção de uma nova alternativa passa, necessariamente, pela revisão das bases conceituais que dão sustentação ao paradigma de amamentação que embasa a política pública de saúde e as formulações dos diferentes grupos sociais ${ }^{1}$.

\section{Amamentação: reflexões conceituais}

Um dos possíveis caminhos para rever a base conceitual que dá sustentação ao atual modelo de amamentação consiste em recorrer à literatura científica para responder a uma indagação básica: por que amamentar?
Após uma breve incursão, já é possível observar que o conhecimento científico oferece respostas de amplo espectro, que vão desde as propriedades biológicas ímpares do leite humano até as questões de cunho econômico, capazes de causar impacto tanto à família quanto ao Estado. Além de revelar a pluralidade que permeia o tema, essas respostas trazem consigo a curiosa unanimidade de apresentarem contornos agrupáveis, que as tornam partícipes de uma mesma trama - a amamentação. O elo comum que permite essa interligação, apontado por vários autores, consiste nas vantagens que a amamentação possibilita para a criança, a mulher, a família e o Estado ${ }^{1}$. Assim, à luz do conhecimento científico, a resposta para a pergunta inicial tem um nome: vantagens. Por que amamentar? Porque a criança, a muIher, a família e o Estado, todos, indistintamente, são amplamente beneficiados com a prática da amamentação direta ao seio.

Contudo, configura-se neste ponto um verdadeiro paradoxo: o desmame. Apesar de as vantagens da amamentação serem apresentadas com contundência pela comunidade científica, e apesar de se observar uma considerável melhora nos índices de amamentação registrados no Brasil entre as décadas de 80 e 90 , observa-se também que existe uma espécie de tendência latente ao desmame historicamente presente na sociedade, levando as mulheres a desmamarem os seus filhos de forma precoce ${ }^{5}$. Por que essa propensão a abandonar uma prática que traz múltiplos benefícios e se mostra inigualável na alimentação de lactentes? Como explicar esse paradoxo?

Um fato que vem se tornando cada vez mais evidente é o descompasso entre o avanço do conhecimento científico - que descobre e correlaciona as especificidades do leite humano às peculiaridades fisiológicas do metabolismo do lactente - e a amamentação como prática socialmente instituída. Todas as vantagens da amamentação descobertas pela ciência e difundidas na sociedade não têm sido suficientes para garantir a introjeção de valores culturais capazes de reverter a sempre presente tendência ao desmame. Para tentar responder a esse paradoxal descompasso, várias pesquisas foram desenvolvidas no Brasil, particularmente a partir dos anos 80 . Como resultado da busca para desvendar as razões dessa tendência, inúmeras verdades foram construídas, conferindo ao desmame um caráter multicausal. Orlandi aponta como um dos fatores do declínio do aleitamento materno as mudanças da estrutura familiar na sociedade moderna urbana. Reforçando esse pensamento, o autor argumenta que a jovem mãe "não tem mais o apoio, a ajuda e o incentivo dos parentes mais velhos (avós, tias, irmãs, etc.), elementos facilitadores do aleitamento materno"6.

A preocupação com a reversão do desmame precoce figura há muito nas agendas de saúde pública. No Brasil, a partir de 1981, essa preocupação deu origem à definição da política estatal em favor da amamentação, materializada como Programa Nacional de Incentivo ao Aleitamento Materno (PNIAM) ${ }^{7}$. O eixo que norteou o delineamento das ações do PNIAM se fundamentava em resgatar a prática da amamentação, concebida como nada mais do que um ato 
natural, instintivo, inato, biológico, próprio do binômio mãe-filho, em que a mãe, mamífera, detém a responsabilidade sobre a saúde de sua cria, reproduzindo na íntegra a concepção higienista de amamentação, construída pela medicina no século $19^{2}$. O paradigma de amamentação adotado pelo PNIAM reduzia as questões relativas ao aleitamento materno à dimensão biológica e, ao tratar o paradoxo do desmame, foi incapaz de admitir a assimetria entre os humanos e as demais espécies de mamíferos, insistindo que o ato de amamentar deveria ser considerado como instintivo, natural e biológico ${ }^{5}$.

A necessidade de rever o modelo de amamentação adotado pela política estatal transformou-se em objeto de construção para vários autores. Orlandi ${ }^{6}$ estima que, apesar de ser aceita a importância da mulher na promoção da amamentação, o campo das políticas nem sempre reflete a ótica desse ator social. Conclui: "Seja como for, os seios, por muito tempo, despertarão um interesse político. Mas é preciso lembrar que eles pertencem às mulheres e que elas não são chamadas a opinar e a decidir na política do aleitamento materno desde o século 18 . No século 20 , os homens continuam cometendo os mesmos erros"6.

Nakano ${ }^{8}$, estudando as representações da amamentação, ratifica as construções de Silva ${ }^{9}$ ao concluir que as mulheres se manifestam por um sentimento ambíguo e contraditório, que oscila entre o desejo e o fardo. Mesmo as mulheres que vêem a amamentação como um ato biologicamente determinado percebem limites em sua prática e sentem a necessidade de desenvolver um aprendizado, evidenciando que o ato de amamentar não é assim tão instintivo ${ }^{5}$.

Almeida ${ }^{1}$, trabalhando as oportunidades assistenciais voltadas para o apoio à lactação adotiva, ao indagar uma mãe não-biológica sobre as razões do sucesso na amamentação de sua filha, obteve como resposta: "A receita do sucesso eu não sei, contudo eu acredito que, para que uma mãe consiga amamentar, independente dela ser adotiva ou não, ela precisa ser antes de mais nada acolhida pelo profissional de saúde (...). Acho que, para amamentar, ela precisa, em verdade, ser amamentada, ela precisa ser acolhida, ela precisa de peitos... de peitos à beça".

Cabe questionar quantos dos profissionais de saúde, dos serviços de saúde, das estruturas sociais de apoio e das instâncias de deliberação política estão de fato preparados para ecoar os anseios deste depoimento.

Neste mesmo sentido, vale destacar um outro estudo, voltado para a avaliação do autodesempenho da mãe profissional de saúde que trabalhava com incentivo ao aleitamento materno antes de se tornar mãe no curso da amamentação de seu próprio filho. Os resultados revelaram que $60 \%$ das mulheres entrevistadas optaram pelo parto cirúrgico sem indicação clínica e que $71,4 \%$ introduziram leites industrializados antes do sexto mês de vida do bebê ${ }^{1}$. O patente descompasso entre o discurso e a prática, entre o fato e a teoria, leva-nos ao tradicional postulado: "faça o que eu digo, mas não o que eu faço". Por que mulheres profissionais, capacitadas para assistir outras mulheres na amamentação, não foram capazes de efetivar o processo consigo mesmas? O estudo citado deu voz às entrevistadas:

"Acho que eu não me sentia segura de impedir que outras pessoas decidissem por mim... eu me senti muito frágil. Eu esperava o apoio de pessoas que não me deram... pessoas do trabalho (...)."

"Eu senti essa falta, de uma pessoa (...). Não para dizer que... o leite é isso, apojadura é aquilo, isso eu sei! Entendeu? Talvez a importância para a mãe não é saber que o leite vem do alvéolo, talvez isso não seja o mais importante."

Em verdade, a mulher precisa ser assistida e acompanhada para que possa desempenhar a bom termo o seu novo papel social, o de mulher-mãe-nutriz. Para tanto, fazem-se exigir estruturas assistenciais preparadas para atuar efetivamente no apoio à mulher e a seu filho. Esse apoio será tão mais efetivo quanto maior for a capacidade do serviço para lidar com a ambigüidade que se apresenta à mulher na relação que se estabelece entre o poder e o querer amamentar, como uma questão de assumir riscos ou garantir benefícios ${ }^{4}$.

\section{Amamentação: a relação entre o biológico e o social}

$\mathrm{Na}$ tentativa de ampliar a compreensão sobre os determinantes do desmame precoce, vários trabalhos foram realizados, em diferentes épocas e regiões do país. Nos estudos em que se buscou compreender o desmame com base no que a mulher verbaliza, permitindo que ela manifeste sua verdadeira razão para o abandono da amamentação, o leite fraco ou pouco leite figuram como principal fator explicativo ${ }^{1}$. Contudo, as disfunções lactogênicas mamárias são raras, o que permite refutar com fundamento científico as teses da hipogalactia e da existência de leite fraco ${ }^{1}$.

Diante do exposto, uma pergunta pertinente continua sem resposta: se não existe leite fraco e a hipogalactia não passa de retórica, visão parcial ou estratégia textual, o que de fato é fraco? Para tentar lançar luz sobre essa questão, torna-se necessário compreender como a sociedade brasileira representou a amamentação no decurso de sua história. Faz-se necessário estabelecer e compreender a rede que se estende em torno da amamentação ${ }^{10}$, desde a chegada dos colonizadores no país, interligando, como partícipes de uma mesma trama: os valores pertencentes às diferentes culturas que concorreram para a formação da sociedade brasileira, em seus diferentes estágios; a política estatal; a medicina; as questões econômicas; o avanço do conhecimento científico sobre a temática; a indústria de leites e fórmulas infantis; os serviços de saúde; e a sociedade civil organizada, na figura das organizações nãogovernamentais e de entidades representativas de classe. Obviamente, esses fatores têm um poder de interferência diferenciado e pesam diferentemente no contexto da construção da amamentação.

Por meio da análise compreensiva dos fatores socioculturais, capazes de interferir na produção do conhecimento 
e nas práticas que se articulam no âmbito da amamentação, pode-se estabelecer uma nova forma de discutir a temática no cenário da saúde pública e, assim, contribuir para o estabelecimento de bases que permitam uma melhor resolutividade na formulação de estratégias para a área.

\section{O Brasil importa a cultura do desmame}

A carta de Pero Vaz de Caminha ao Rei de Portugal contém o que certamente pode ser considerado o primeiro relato sobre a amamentação no Brasil - "... com um menino ou menina ao colo, atado com um pano (não sei de quê) aos peitos..."9.

A alusão ao fato de as mulheres indígenas amamentarem seus filhos denota o estranhamento dos "descobridores" frente a uma prática do "novo mundo", cuja civilização européia já havia proscrito. Historicamente, situa-se aí o primeiro embate cultural em torno da amamentação no Brasil. O ato de aleitar direto ao seio, cultivado pelos integrantes da sociedade tupinambá, certamente foi percebido pelos portugueses como um comportamento instintivo e natural, impróprio para o homem civilizado, cujo padrão de referência comportamental circunscrevia-se aos hábitos e costumes da cultura européia ${ }^{1}$.

$O$ regime alimentar do lactente nos idos de 1500 acompanhava o desenvolvimento da marcha. Na fase de colo, a criança tinha a sua alimentação basicamente restrita ao seio materno, muito embora recebesse da mãe a oferta de uma massa de grãos de milho, por ela mastigada e prédigerida pela ptialina. Contudo, a índia não estimulava o apetite do filho. A massa de amido era colocada nas mãos do bebê, que, por sua vez, decidia levar ou não à boca o alimento que estava a seu alcance. Uma vez desenvolvida a marcha, a criança passava a se valer da comida dos adultos, mas sem abandonar o peito da mãe ${ }^{9}$.

O aleitamento se prolongava por mais de 2 anos, merecendo destaque o fato de a prática do desmame ser efetivada a partir da dieta dos pais, respeitando, assim, o hábito alimentar da família. Apesar da exaustiva revisão de literatura, não foi possível acessar registros que denotassem a utilização de leite de outras espécies animais no curso do desmame, entre os índios, no período do descobrimento do Brasil. Vale destacar ainda que os relatos sobre desnutrição e mortalidade entre lactentes indígenas brasileiros só passaram a existir a partir do momento em que se ampliou a convivência com o branco ${ }^{1}$.

A ocorrência de desmame precoce restringia-se a três situações: morte materna, doença grave da mãe ou nos casos interditados pela cultura. A cultura impedia a amamentação nas situações em que o rebento era considerado indesejável, ou seja, quando se tratava de filhos de inimigos com mulheres da tribo ou filhos de índias que mantinham relações sexuais com mais de um parceiro ${ }^{9}$. O trabalho materno não se configurava fator de desmame, apesar de a sociedade indígena imputar uma carga de trabalho para a mulher superior à do homem. Com o auxílio da tipóia, a índia conseguia harmonizar seu duplo papel: de mãe-nutriz e de mulher-trabalhadora ${ }^{9}$.
Assim, no Brasil, o aleitamento materno entre os índios tupinambás era a regra geral até a chegada dos descobridores europeus, que trouxeram, em sua bagagem cultural, o hábito do desmame. Para as mulheres européias daquela época pertencentes às classes sociais dominantes, o amor materno não tinha valor social e moral, fato que as levava a considerar a amamentação uma tarefa indigna para uma dama. Esse comportamento tendia a ser copiado pelas demais classes como forma de distinção social ${ }^{11}$. Em Lisboa, a amamentação mercenária era uma prática socialmente instituída, e cabia às saloias, camponesas da periferia, o aleitamento dos filhos das classes sociais dominantes ${ }^{1}$.

Em resumo, Portugal transmitiu ao Brasil o costume das mães ricas de não amamentarem seus filhos e, conseqüentemente, a necessidade de instituir a figura da saloia. As índias cunhãs constituíram a primeira versão de saloias brasileiras; porém, em razão da rejeição cultural que apresentavam, foram substituídas pelas escravas africanas ${ }^{1}$. Mais tarde, a urbanização ampliou a difusão das amas-de-leite entre as novas camadas sociais e fez com que surgisse a figura da mãe preta de aluguel ${ }^{3}$. A importância atribuída a esse novo ator social assumiu tamanha proporção que alguns senhores de escravos chegaram a admitir que criar negras para alugar como amas era mais rentável do que plantar café ${ }^{12}$. Essa nova versão de aleitamento mercenário, impregnada de uma estratégica mercantilista, foi exercida no Brasil em um momento histórico, muito anterior à chegada dos leites industrializados. É secular, portanto, a tendência de se procurar auferir lucros com práticas que gravitam em torno da amamentação, estimulando propositadamente a instituição do desmame ${ }^{1}$.

\section{A amamentação sob o olhar da medicina higienista}

O século 19 foi marcado, dentre outros aspectos, pela consolidação do novo papel social da medicina, que ampliou o seu domínio para além da exclusiva preocupação com o corpo. A alimentação, as condições ambientais e o comportamento humano passaram a se configurar em objetos de preocupação médica, na busca de soluções para problemas como a mortalidade infantil. Essa trajetória, desde seu início, foi pautada pela formulação de regras rígidas impostas à família e, sobretudo, à mulhermãe, no intuito de modular o seu comportamento em favor da saúde da criança ${ }^{1}$.

Ao conjunto de técnicas de persuasão e estratégias de ataque, a medicina social deu o nome de higiene familiar. Dentre as regras básicas, o binômio mãe-filho foi uma das mais brilhantes equações desenvolvidas pelos higienistas, e, por intermédio deles, a higiene elevou a mulher à categoria de mediadora entre os filhos e o Estado. Os higienistas reconstruíram socialmente a biologia do ciclo gravídico-puerperal, buscando resgatar, na ordem natural do instinto, a maternidade e a amamentação como fatores vitais para a sobrevida dos filhos ${ }^{1}$. Os higienistas passaram a condenar rigorosamente o aluguel de escravas como amas-de-leite. A maioria das críticas feitas à mortalidade 
infantil foi por meio de trabalhos médicos sobre amamentação, cuja tônica não era o destino dos filhos das escravas, e sim a saúde dos bem-nascidos ${ }^{1}$.

$\mathrm{O}$ ato de amamentar prestava-se a regular a vida da mulher no universo disciplinar imposto pela normalização higiênica. Sob esse enfoque, o primeiro objetivo disciplinar da amamentação foi o de regular o tempo livre da mulher na casa, livrando-a do ócio e dos passatempos nefastos à moral e aos bons costumes familiares. A amamentação também se prestou para deter a mulher no lar e arrefecer a independência feminina decorrente da emancipação do patriarcado. O discurso higiênico sobre a amamentação orientou-se por comprometer as mulheres com a política de utilização "machista" do homem, fazendo-as crer na nobreza da função de amamentar ${ }^{3}$. A circunscrição da sexualidade feminina à zona de controle higienista envolveu várias manobras, e a limitação do ato sexual no curso da amamentação foi uma das mais bem-sucedidas. As restrições justificavam-se, segundo a lógica da medicina social, por evitar uma nova concepção que comprometeria a secreção lática e pelo fato de a própria relação sexual ser capaz de corromper as qualidades do leite ${ }^{1}$.

A medicina higienista se valeu do aleitamento materno como instrumento para se fortalecer junto à sociedade e colonizar progressivamente a família, tornando-a cada vez mais dependente dos agentes educativo-terapêuticos. A amamentação foi construída socialmente a partir de atributos naturais e instintivos, comuns às espécies definidas como mamíferos. Dessa forma, para atender a fins estratégicos, a medicina social fundou a prática da amamentação natural sob a égide do determinismo biológico, desconsiderando propositadamente, em seu favor, a magnitude dos condicionantes socioculturais que permeiam essa prática.

\section{Leite fraco: nasce a regra para a exceção}

Todo o conjunto de regras poderia ser emblematicamente resumido em um único slogan, que certamente traduz todo o espírito da filosofia higienista a respeito da amamentação: "A saúde de seu filho depende de você. Amamente" ${ }^{\prime 1}$.

Com as regras, nasceram as exceções. Registros de 1869 revelam que certos grupos de mulheres não conseguiam amamentar em virtude do pequeno volume de leite produzido, de este ser fraco ou pelo fato de secarem com facilidade. Essa situação de insucesso frente ao cumprimento de todas as regras se configurou em um problema para o qual o modelo higienista não dispunha de resposta. Para contornar essa crise paradigmática, o higienismo criou e introjetou na cultura brasileira a figura do leite fraco ${ }^{1}$. Mas como o processo de difusão de um elemento cultural envolve três etapas - apresentação, aceitação e integração ${ }^{13}$-, vale questionar sobre os fatores presentes na cultura receptora que favoreceram a incorporação desse novo elemento.

Um modelo explicativo pode ser formulado colocando a dificuldade materna de assumir o insucesso da amamentação frente à forte censura social para o desmame imposta pelos higienistas. A incapacidade de amamentar tornaria pública a impossibilidade de cumprir uma "função natural e dever sagrado", inferiorizando a mulher perante a sociedade. Por outro lado, uma "epidemia" de exceções colocaria em crise o paradigma higienista, incapaz de solucionar esses novos problemas com as regras instituídas. Assim, torna-se pelo menos razoável supor que a instituição da figura de um novo ator social, capaz de assumir todas as culpas, configurar-se-ia em uma estratégia interessante para contornar o problema então emergente. Esse tipo de alternativa, mais do que suavizar a responsabilidade materna, manteria imaculado o modelo higienista de amamentação ${ }^{1}$.

\section{Os primeiros efeitos da urbanização}

As mudanças nas atividades econômicas do país decorrentes do fim da escravidão formal terminaram por atribuir uma importância econômico-política ao aleitamento, levando o Estado, pela primeira vez, a se pronunciar em favor da criança pobre. Por ser considerada um poderoso meio de sobrevivência infantil, as autoridades propuseram que a amamentação fosse estimulada junto aos segmentos mais pobres da sociedade, como estratégia de ampliação de mão-de-obra para o capitalismo exportador ${ }^{14}$.

Por outro lado, as pressões sociais da urbanização e a crescente inserção da mulher pobre no mercado de trabalho teciam um cenário favorável ao desmame. Em meio a essas transformações, foi se desenvolvendo a sociedade de consumo, e, com ela, surgiu a mamadeira, um dos novos símbolos de modernidade e urbanismo ${ }^{15}$. Nessa mesma época, chegaram ao Brasil as primeiras remessas de leite condensado e farinha láctea, importados da Suíça. A mistura desses dois ingredientes, mamadeira e leite industrializado, possibilitou a configuração de uma alternativa terapêutica para a antiga impossibilidade clínica de amamentar: o leite fraco. Assim, sob a égide do avanço do conhecimento científico, construiu-se a hipogalactia, a nova doença que, além de se transformar numa das principais preocupações para a medicina no início do século 20, configurou-se como o mediador que permitiu a institucionalização do desmame precoce como uma prática sociocultural, sob os auspícios da medicina $^{1}$.

\section{Vanguarda científica e modernidade: o emblema dos leites industrializados}

A propaganda enganosa dos sucedâneos do leite materno em revistas especializadas, a utilização de profissionais de saúde como promotores de venda no ambiente hospitalar, a publicação de informes técnicos direcionados principalmente a puericultores e a promoção de eventos científicos se configuraram, há até muito pouco tempo, em elementos que compunham a estratégia de marketing das empresas. Como resultado, o médico absorveu completamente a idéia de que o leite materno precisava ser complementado, mesmo nas situações em que não se diagnosticava hipogalactia. A prescrição freqüente dos leites industri- 
alizados passou a figurar como elemento de profilaxia da desnutrição infantil ${ }^{15}$.

A indústria construiu elementos culturais de valorização do leite em pó, introjetados na sociedade brasileira através de estratégias voltadas prioritariamente para os que detinham o poder de prescrever o regime alimentar do lactente: os pediatras. Os novos produtos foram difundidos como resposta às descobertas sobre as necessidades nutricionais, resultantes do avanço do conhecimento científico em relação às peculiaridades do metabolismo da criança. Logo, se o conhecimento científico avançava, a prática diária do puericultor deveria seguir o mesmo caminho. Assim, a indústria se apropriou da ciência da nutrição e, por meio de recortes específicos, criou retóricas e abordagens semióticas para a construção da verdade acerca de seus produtos ${ }^{1}$.

As instituições coletivas de solidariedade social, por sua vez, corroboraram a instituição do desmame precoce. O Estado se valeu de suas agências de assistência social e dos centros de saúde para implementar programas de distribuição de leite em pó para a população de baixa renda ${ }^{16}$. As mudanças nas representações sobre o papel da mulher na sociedade, a emancipação feminina, as contradições sobre o trabalho e a vida reprodutiva constituíram outro conjunto de fatores que interferiram simultaneamente no condicionamento sociocultural da amamentação ${ }^{11}$. Esses fatores foram apropriados pela indústria de leites modificados no intuito de embasar socioculturalmente o paradigma do desmame comerciogênico, que norteou a alimentação de lactentes no Brasil até o final dos anos $70^{1}$.

\section{Mudanças nas percepções sociais}

O desenvolvimento do PNIAM desencadeou um movimento de valorização da prática da amamentação na sociedade brasileira a partir do início década de 80 . A superioridade do aleitamento materno se transformou em unanimidade no meio científico e foi amplamente divulgada para o público em geral por intermédio de campanhas nos meios de comunicação de massa. A medicina, sobretudo a pediatria, redescobriu as vantagens da amamentação e, sob a égide da ciência, redesenhou o conhecimento com o rigor do método, no intuito de compatibilizar as peculiaridades fisiológicas do metabolismo do lactente com as descobertas acerca das propriedades biológicas ímpares do leite humano. Além dos aspectos nutricionais e imunológicos que beneficiam a criança, as vantagens do aleitamento para mãe, família, sociedade e Estado foram trazidas a relevo e transformadas em instrumento de marketing em favor da amamentação ${ }^{17}$.

A mobilização social pró-amamentação constituiu um dos fatores de maior destaque no cenário da promoção do aleitamento materno no Brasil. O PNIAM foi capaz de articular e congregar esforços dos mais diferentes segmentos da sociedade brasileira. Órgãos de governo, sociedades de classe, organizações não-governamentais, empresas privadas, veículos de comunicação de massa e associações comunitárias compuseram uma verdadeira "torre de babel ideológica", conferindo o que havia de mais rico nas ações em favor do aleitamento: o sentido plural ${ }^{1}$.
Com isso, a indústria perdeu o seu tradicional espaço e passou a se defrontar com um crescente estreitamento de mercado. Como não havia mais condições de tentar superar as vantagens da amamentação natural com o endosso da ciência, os fabricantes de leites modificados elegeram um novo nicho mercadológico, construindo socialmente a biologia da excepcionalidade no cenário da amamentação. Essa nova categoria possibilitou a reedição da antiga fórmula "vanguarda científica" no campo da alimentação e nutrição de recém-nascidos ${ }^{1}$. A principal diferença entre os dois modelos, o do desmame comerciogênico, praticado entre as décadas de 40 e 70, e o da excepcionalidade, praticado atualmente, situa-se no sujeito-objeto de construção da "vanguarda científica". O paradigma do desmame comerciogênico contemplava todos os recém-nascidos como potenciais consumidores, enquanto que o modelo da excepcionalidade se volta, em princípio, para aqueles que vivenciam situações particulares, a exemplo da prematuridade e de alergias alimentares. A indústria passou a criar espaços que possibilitassem a construção de verdades supostamente embasadas pela ciência, todas amplamente favoráveis a seus produtos e sugestivamente contrárias à utilização do leite humano ${ }^{1}$. Essas novas verdades foram construídas a partir de recortes específicos do conhecimento científico e possibilitaram abordagens parciais pelas estratégias de marketing ${ }^{18}$.

A implementação do Programa Iniciativa Hospital Amigo da Criança no Brasil, a partir de 1992, trouxe um novo fôlego para o aleitamento materno no circuito das políticas públicas. Apesar das restrições ao modelo, entre as quais a inobservância à hierarquização da rede de saúde no país, há de se ressaltar o fato de essa iniciativa ter incorporado o significado de proteção e apoio à amamentação, superando as formulações que anteriormente só contemplavam aspectos relativos à promoção. Ao se focalizar a amamentação com as lentes da relação promoção-proteção-apoio, tornam-se visíveis os contornos que a caracterizam como um fato social, cuja historicidade revela o equívoco das formulações políticas que a contemplaram como uma prática natural ${ }^{1}$.

Esta nova forma de pensar a amamentação, além de mais abrangente, exige que se estabeleça um novo foco sobre a mulher, que não pode continuar a ser tratada como sinônimo de mãe-nutriz, responsável pelo êxito da amamentação e culpada pelo desmame. O desafio da construção de um modelo que possa responder a essa demanda, contextualizando as questões da amamentação às circunstâncias decorrentes da pós-modernidade, passa obrigatoriamente pela capacidade de compatibilizar os determinantes biológicos com os condicionantes socioculturais, os quais configuram a amamentação como uma categoria híbrida entre a natureza e a cultura.

\section{O híbrido natureza-cultura: considerações finais}

Da carta de Pero Vaz de Caminha ao rei de Portugal à emblemática vanguarda científica construída socialmente pelos fabricantes de leites modificados, a amamentação revelou e revela diferentes significados, que oscilam em 
torno de dois pólos: natureza e cultura. A depender do momento e da finalidade de seu uso, esses significados ora se separam, ora se fundem. Às vezes, esses dois aspectos se associam de maneira tão intensa que um assume a denominação do outro, ou seja, para que a amamentação possa ser perpetuada como um hábito cultural, ela deve ser assimilada como algo que faz parte da natureza, não cabendo nenhum questionamento. Outras vezes, deparase com interpretações culturais que não aceitam reduzir o ser humano à condição de um mamífero qualquer, redirecionando e redimensionando o próprio movimento natural da espécie humana.

Na direção de um posicionamento que recusa a redução, tanto na dimensão biológica quanto na social, a categorização da amamentação como um híbrido natureza-cultura procura perseguir uma abordagem da amamentação como reflexo de determinantes biológicos e condicionantes sociais, econômicos, políticos e culturais. Este movimento, contrário à dicotomia costumeira estabelecida entre o biológico e o social, gera novas oportunidades teóricometodológicas na forma de operar com as questões que permeiam a amamentação, possibilitando uma revalorização da biologia e um aprofundamento nos processos interdisciplinares que permeiam a temática.

\section{Referências}

1. Almeida JAG. Amamentação: um híbrido natureza-cultura. Rio de Janeiro: FIOCRUZ; 1999.

2. Almeida JAG. Leite fraco: um problema da mama ou da cultura. Masto-Magazine. 1998;2:2.

3. Costa JF. Ordem médica e norma familiar. Rio de Janeiro: Graal; 1983.

4. Silva IA. Amamentar: uma questão de assumir riscos ou garantir benefícios. São Paulo: Robe Editorial; 1997.

5. Almeida JAG, Gomes R. Amamentação: um híbrido naturezacultura. Revista Latino-Americana de Enfermagem. 1998;6:71-5.
6. Orlandi OV. Teoria e prática do amor à criança: introdução à pediatria social no Brasil. Rio de Janeiro: Jorge Zahar; 1985.

7. Monson MRR. Os bancos de leite e a política de aleitamento materno na década de oitenta no Brasil (filme-vídeo). 1 cassete VHS, 34min., color., sonoro. Rio de Janeiro: Núcleo de Vídeo CICT/Fundação Oswaldo Cruz; 1992.

8. Nakano AMS. O Aleitamento materno no cotidiano feminino [tese]. Ribeirão Preto: Universidade de São Paulo; 1996.

9. Silva AAM. Amamentação: fardo ou desejo? Estudo históricosocial dos saberes e práticas sobre aleitamento materno na sociedade brasileira [dissertação]. Ribeirão Preto: Universidade de São Paulo; 1990.

10. Latour B. Jamais fomos modernos: ensaio de antropologia simétrica. Rio de Janeiro: 34 Literatura S/C Ltda; 1994.

11. Badinter E. Um amor conquistado: o mito do amor materno. Rio de Janeiro: Nova Fronteira; 1985.

12. Ewbank T. Vida no Brasil ou diário de uma visita à terra do cacaueiro. São Paulo: Edusp; 1976.

13. Linton R. O Homem: uma introdução à antropologia. São Paulo: Martins Fontes; 1981.

14. Almeida JAG. Aleitamento materno: uma visão sócio-cultural. In: Anais do I Congresso do Cone Sul de Aleitamento Materno [Compact disc data storage]. 1 CD, colorido, sonoro. Joinville: Videolar - Grupo Origem; 1996.

15. Goldemberg P. Repensando a desnutrição como questão social. Campinas: Editora Unicamp; 1988.

16. Goldemberg $P$, Tudisco ES. Desnutrição: a penetração do leite em pó através da propaganda. Ciência Hoje 1983;1:76-9.

17. Souza LMBM. Do leite fraco à biologia da excepcionalidade - as múltiplas faces da mesma moeda [tese]. Rio de Janeiro: Instituto Fernandes Figueira/FIOCRUZ; 2003.

18. Minayo MCS. O Desafio do conhecimento: pesquisa qualitativa em saúde. São Paulo: HUCITEC; 1994.

Correspondência:

João Aprigio Guerra de Almeida

Av. Rui Barbosa, 716, Flamengo

CEP 22250-020 - Rio de Janeiro, RJ

Fone/Fax: (21) 553.5669

E-mail: joaoaprigio@globo.com 